\title{
Vestibular bone thickness of the mandible in relation to the mandibular canal in a population from Bosnia and Herzegovina
}

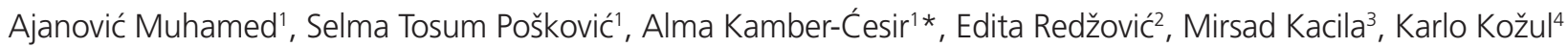 \\ ${ }^{1}$ Department of Prosthodontics, Faculty of Dentistry, University of Sarajevo, Sarajevo, Bosnia and Herzegovina, ${ }^{2}$ Faculty of Dentistry, University \\ of Sarajevo, Sarajevo, Bosnia and Herzegovina, ${ }^{3}$ Specialized Hospital "Heart Center," Sarajevo, Bosnia and Herzegovina, ${ }^{4}$ Department of \\ Epidemiology, Faculty of Medicine, University "J.J. Strossmayer," Osijek, Croatia
}

\section{ABSTRACT}

Introduction: Dental implantology is the branch of dentistry that is gaining greater significance because a larger number of patients come with requests of implant placements. During dental implant placements, with patients with whom operation is carried out in the mandible, very frequently nervus alveolaris inferior can be injured. The nerve injury may occur during the implant placement, but the nerve may also be injured in case of harvesting of intraoral bone graft. During the bone graft harvesting, but also during any other procedure in the dentistry that entails working on vestibular side of corpus of the mandible, in order not to injure the nervus alveolaris inferior, it is important to familiarize oneself with the distance of the nerve from the outer vestibular cortex of the mandible. The objective of the study was to assess the vestibular bone thickness of the mandible in relation to the mandibular canal with the help of analysis of cone-beam computed tomography (CBCT) images.

Methods: It was accessed the database of $\mathrm{CBCT}$ images taken at the School of Dental Medicine at the University of Sarajevo, where out of 700 reviewed CBCT image, an analysis of 322 CBCT images was conducted that satisfied inclusion criteria of the study. CBCT images were taken using of ORTHOPHOS SLX imaging unit. The measurement was conducted by Sidexis program on cross-section of CBCT image. The measurement of vestibular bone thickness was performed, by measuring the distance from the lateral wall of the mandibular canal to buccal mandibular compact bone, in the region of the second premolar, of the first and the second molar.

Results: There were statistically significant differences in vestibular bone thickness between men and women on both sides in the region of the second premolar $(p<0.001)$ and first molar $(p=0.016$ right, $p=0.018$ left). T-test demonstrated no statistically significant difference in the vestibular bone thickens between men and women on either side in the case of vestibular bone thickness of the center of the second molar ( $p=0.397$ right, $p=0.743$ left).

Conclusion: Values of vestibular thickness of the mandible are larger with men than with women in all measuring points; however, statistically more significant differences between genders have been detected in the second premolar and center of the first molar.

Keywords: Cone-beam computed tomography, mandibular canal, vestibular thickness

\section{INTRODUCTION}

Dental implantology is the branch of dentistry that is gaining greater significance because a larger number of patients come with requests of implant placements. During dental implant placements, with patients with whom operation is carried out in the mandible, very frequently nervus alveolaris inferior can be injured (1-4). The nerve injury may

*Corresponding author: Alma Kamber-Ćesir, Department of Prosthodontics, Faculty of Dentistry, University of Sarajevo, Bolnička 4a, Sarajevo, Bosnia and Herzegovina. E-mail: akamber@sf.unsa.ba

Submitted: 24 March 2021/Accepted: 07 May 2021

DOI: https://doi.org/10.17532/jhsci.2021.1293 occur during the implant placement, but the nerve may also be injured in case of harvesting of intraoral bone graft that is most frequently taken from the area of the mandible when it is necessary to compensate the bone deficiency so that the implant placement could be as successful as possible $(5,6)$.

Intraoral bone harvesting has more advantages in relation to extraoral bone harvesting. The advantages are reflected in better surgical approach, shorter time of surgery, general anesthesia is not necessary, it concerns an outpatient procedure with no scars, it is more comfortable for a patient, and the bone harvesting from the area of maxillofacial region has better biological benefits for the augmentation $(7,8)$. This implies bone harvesting most frequently from the area of ramus of the 
mandible, but corpus as well, mandibular symphysis, residual ridge of the mandible, and the processus coronoideus (7,9-12).

During the bone graft harvesting, but also during any other procedure in the dentistry that entails working on vestibular side of corpus of the mandible, in order not to injure the nervus alveolaris inferior, it is important to familiarize oneself with the distance of the nerve from the outer vestibular cortex of the mandible $(5,6)$. Before any surgical technique that is planned to be executed in the area of the mandible, with the aim of identification of exact location of anatomic structures, it is necessary to make appropriate radiographic imaging (13-15).

In that regard, in the last couple of decades as one of the newest and the best imaging techniques that enable more exact identification of the anatomic structures is cone-beam computed tomography (CBCT) that represents $3 \mathrm{D}$ imaging modality that is obtained through cone-beam of certain areas and that can be reconstructed in any desired plane such as axial, sagittal and coronal plane, and information may be reconstructed both panoramically and in cross-sections $(16,17)$. The aim of the study was to assess the vestibular bone thickness of the mandible in relation to the mandibular canal with the help of analysis of CBCT images.

\section{METHODS}

Within research, it was accessed the database of CBCT images taken at the School of Dental Medicine at the University of Sarajevo in the period from 2017 to April 2020, taken for various dentistry purposes, where out of 700 reviewed CBCT image, an analysis of 322 CBCT images was conducted that satisfied inclusion criteria of the study.

The inclusion criteria included the following:

1. Acceptable image quality

2. Representation of the entire mandible at the image

3. Clearly detectable and represented nervus alveolaris inferior at the image

The exclusion criteria included the following:

1. Irregular volume of the bone and presence of pathological changes in the measurement region such as cysts, tumors, and periapical lesions

2. Presence of the mandible fracture

3. Disturbed course and continuity of nervus alveolaris inferior

4. Impacted and semi-impacted teeth in the measurement region

5. Patients younger than 14 years old.

Study is approved by Ethical committee of University of Sarajevo - Faculty of Dentistry. The purpose of the research was presented to all patients and they gave consent to use their individual data in this study. Patients were grouped according to age into three age groups $(1=14-34$ years, $2=35-50$ years, $3=$ more than 50 years).

CBCT images were taken using of ORTHOPHOS SLX imaging unit. Nominal power output of this imaging unit is $2 \mathrm{~kW}$ during $90 \mathrm{kV} / 16 \mathrm{~mA}$, nominal frequency $50 \mathrm{~Hz} / 60 \mathrm{~Hz}$. The tube voltage is $60-90 \mathrm{kV}$ (for $90 \mathrm{kV}$ max. $12 \mathrm{~mA}$ ) and the power in tube is $3-16 \mathrm{~mA}$ (for $16 \mathrm{~mA} \max .69 \mathrm{kV}$ ). The frequency of generation of creating a high voltage is $40-120 \mathrm{kHz}$. Time of exposure to image is maximum 14.9 s. Entire filtration of X-ray tube is $>2.5 \mathrm{~mm} \mathrm{Al} / 90$ IEC $605220.3 \mathrm{~mm} \mathrm{Cu}$. The size of focal point toward IEC 60336, measured in central X-ray, is $0.5 \mathrm{~mm}$.

The measurement was conducted by Sidexis program on a cross-section of CBCT image. The measurement procedure implied the previous mapping of nervus alveolaris inferior, and subsequently in the region of the second premolar, of the first and the second molar with the help of ruler and protractor at a cross-sectional intersection, following the tooth axis (with dentate and partially edentulous patients) and axis of bone (with totally edentulous and partially edentulous patients in areas where teeth are missing) the measurement of vestibular bone thickness was performed (spongiosis + cortical plate), by measuring the distance from the lateral wall of the mandibular canal to buccal mandibular compact bone (Figure 1).

Measuring points along alveolar nerve with dentate and partially edentulous patients in areas where teeth of interest were present: The center of the second premolar as well as centers of the first and the second molar, on both sides of mandible. With partially dentate patients in areas where teeth were missing and with totally edentulous patients, measurements were conducted only on measuring points that were marked as "tooth center" and that were determined with the help of reconstruction methods used in implantology. What was recorded is the minimum vestibular thickness of the mandible, as the shortest possible value between the mentioned two distances, that is, measurement was conducted under the angle of 90 degrees.

The statistic software IBM SPSS Statistics 23 was used to conduct the statistic tests, as well as for the calculation of descriptive statistics. Considering different variables, comparisons, and size of samples of certain groups and subgroups, tests that were used within the study included the following: Kolmogorov-Smirnov test, one-way ANOVA, t-test for independent variables, and post hoc test. P values were considered to be statistically significant at the level 0.05 .

\section{RESULTS}

The sample consisted of 322 CBCT images of 322 patients. Number of subjects in each age group is presented in Figure 2.

The mean and range of age in different dental status are shown in Table 1.

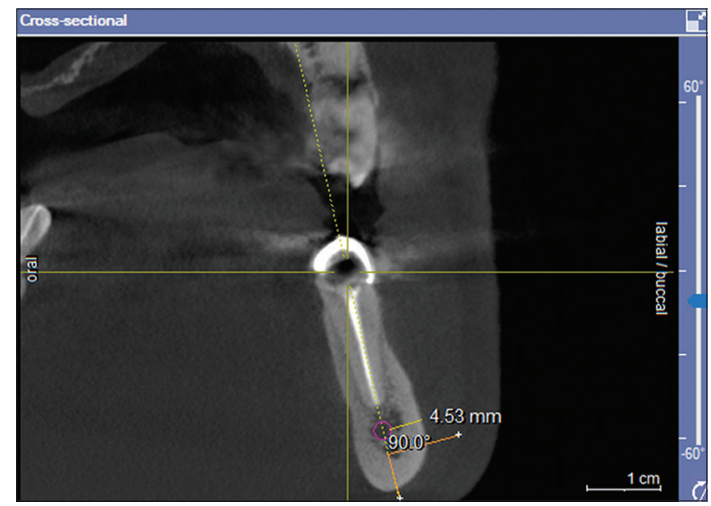

FIGURE 1. Measurement of mandibular bone thickness on cone-beam computed tomography image; the distance from the lateral wall of the mandibular canal to buccal mandibular compact bone. 


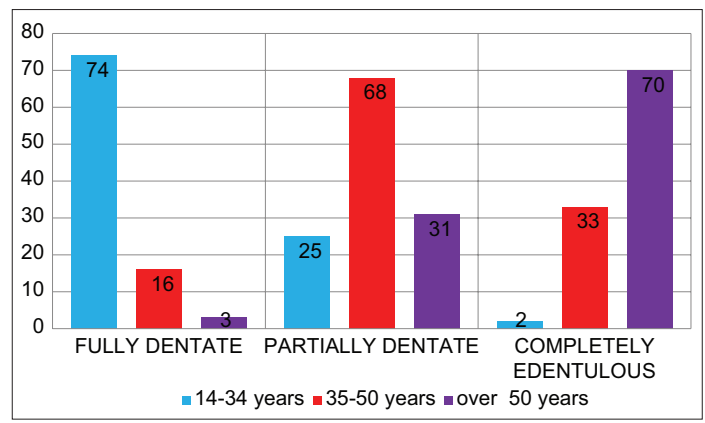

FIGURE 2. Number of subjects in each age group (group 1, 14-34 years old; group 2, 35-50 years old; group 3, 51 and older).

TABLE 1. Values of age according different dental status and gender

\begin{tabular}{|c|c|c|c|c|}
\hline \multirow{2}{*}{$\begin{array}{l}\text { Gender } \\
\text { Men }\end{array}$} & \multirow{3}{*}{$\begin{array}{l}\text { Dental status } \\
\text { Fully } \\
\text { dentatemin }\end{array}$} & \multicolumn{2}{|c|}{ Statistics } & \multirow{2}{*}{$\begin{array}{c}\text { Std. Error } \\
1.939\end{array}$} \\
\hline & & Mean & 28.78 & \\
\hline & & Variance & 154.176 & \\
\hline & & Std. Deviation & 12.417 & \\
\hline & & Minimum & 14 & \\
\hline & & Maximum & 67 & \\
\hline & Partially & Mean & 45.18 & 1.418 \\
\hline & dentate & Variance & 132.705 & \\
\hline & & Std. Deviation & 11.520 & \\
\hline & & Minimum & 19 & \\
\hline & & Maximum & 72 & \\
\hline & Completely & Mean & 55.17 & 1.309 \\
\hline & edentulous & Variance & 89.126 & \\
\hline & & Std. Deviation & 9.441 & \\
\hline & & Minimum & 40 & \\
\hline & & Maximum & 84 & \\
\hline \multirow[t]{15}{*}{ Women } & Fully dentate & Mean & 24.37 & 1.172 \\
\hline & & Variance & 71.452 & \\
\hline & & Std. Deviation & 8.453 & \\
\hline & & Minimum & 14 & \\
\hline & & Maximum & 46 & \\
\hline & Partially & Mean & 43.43 & 1.477 \\
\hline & dentate & Variance & 126.460 & \\
\hline & & Std. Deviation & 11.245 & \\
\hline & & Minimum & 20 & \\
\hline & & Maximum & 70 & \\
\hline & Completely & Mean & 53.72 & 1.258 \\
\hline & edentulous & Variance & 83.899 & \\
\hline & & Std. Deviation & 9.160 & \\
\hline & & Minimum & 32 & \\
\hline & & Maximum & 70 & \\
\hline
\end{tabular}

Tables 2-4 demonstrate the average values of vestibular thickness for men and women. Men had larger values of vestibular bone thickness of the center of the second premolar (4.43) in relation to women (3.96) on the right side but also on the left side (4.46 vs. 3.90). Furthermore, men (5.97) had larger values of vestibular bone thickness of the center of the first molar in relation to women (5.64) on the right side, but also on the left side ( 5.98 vs. 5.65$)$. Table 4 shows that, as it was the case with the second premolar and first molar, on the position of the center of the second molar, men have the largest average values compared to women on both sides of the mandible.

Kolmogorov-Smirnov test showed the data follow the normal distribution $(p>0.05)$ within each group of subjects,
TABLE 2. Mean values of vestibular thickness of the center of the second premolar with men and women

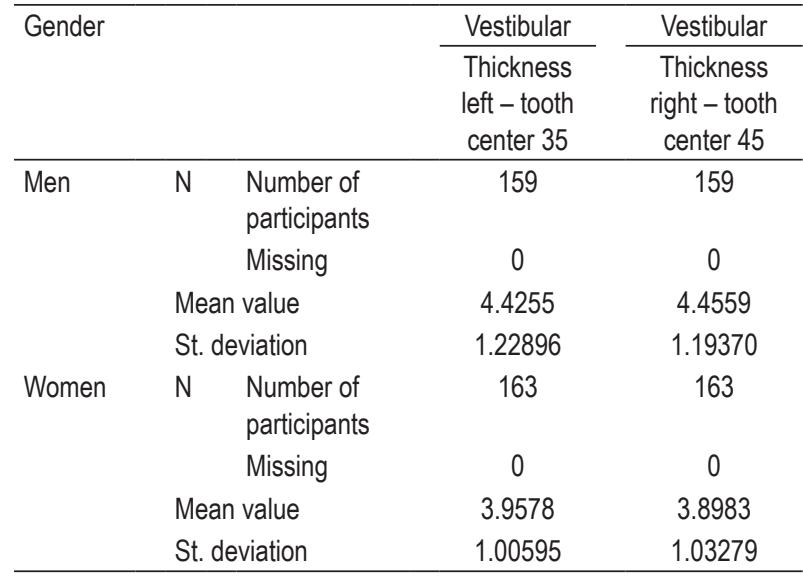

TABLE 3. Mean values of vestibular thickness of the center of the first molar with men and women

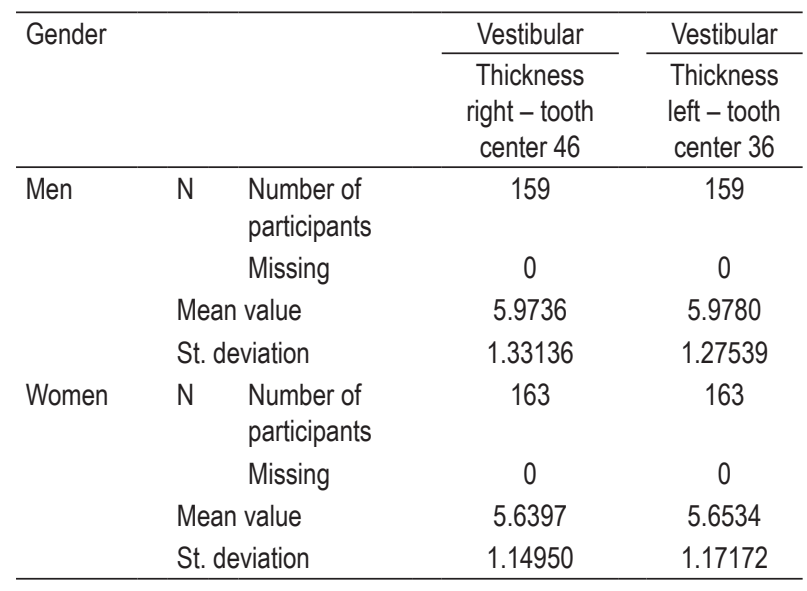

TABLE 4. Mean values of vestibular thickness of the center of the second molar with men and women

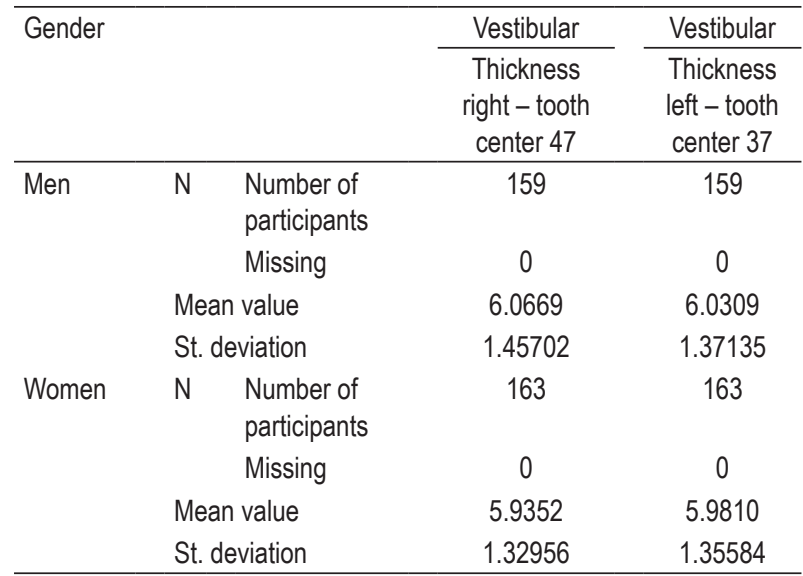

both men and women, for each observed value (Table 5).

T-test demonstrated (Table 6) a statistically significant difference in vestibular bone thickness for the second premolar between men and women on both sides.

In this case, too (Table 7), a statistically significant difference exists in vestibular bone thickness for the first molar between men and women on both sides.

T-test demonstrated no statistically significant difference in the vestibular bone thickness between men and women on 
TABLE 5. The results of one sample Kolmogorov-Smirnov test

\begin{tabular}{|c|c|c|c|c|c|c|c|}
\hline \multicolumn{8}{|c|}{ One-sample Kolmogorov-Smirnov test } \\
\hline Gender & & $\begin{array}{l}\text { Vestibular } \\
\text { thickness } \\
\text { right - tooth } \\
\text { center } 45\end{array}$ & $\begin{array}{c}\text { Vestibular } \\
\text { thickness } \\
\text { left - tooth } \\
\text { center } 35\end{array}$ & $\begin{array}{c}\text { Vestibular } \\
\text { thickness } \\
\text { right - tooth } \\
\text { center } 46\end{array}$ & $\begin{array}{c}\text { Vestibular } \\
\text { thickness } \\
\text { left - tooth } \\
\text { center } 36\end{array}$ & $\begin{array}{l}\text { Vestibular } \\
\text { thickness } \\
\text { right - tooth } \\
\text { center } 47\end{array}$ & $\begin{array}{l}\text { Vestibular } \\
\text { thickness } \\
\text { left - tooth } \\
\text { center } 37\end{array}$ \\
\hline \multirow[t]{3}{*}{ Men } & $\mathrm{N}$ & 159 & 159 & 159 & 159 & 159 & 159 \\
\hline & Test statistics & 0.066 & 0.069 & 0.042 & 0.054 & 0.060 & 0.040 \\
\hline & $p$-value & 0.085 & 0.059 & 0.200 & 0.200 & 0.200 & 0.200 \\
\hline \multirow[t]{3}{*}{ Women } & $\mathrm{N}$ & 163 & 163 & 163 & 163 & 163 & 163 \\
\hline & Test statistics & 0.064 & 0.063 & 0.035 & 0.066 & 0.037 & 0.070 \\
\hline & $p$-value & 0.200 & 0.200 & 0.200 & 0.081 & 0.200 & 0.052 \\
\hline
\end{tabular}

TABLE 6. Results of t-test for independent samples for the vestibular thickness on the position 45 and 35 between men and women

\begin{tabular}{|c|c|c|c|c|}
\hline \multirow[t]{2}{*}{ t-test for independent samples } & Vestibular & Thickness & \multirow{2}{*}{\multicolumn{2}{|c|}{$\begin{array}{l}\text { Vestibular } \\
\text { Left - tooth center (tooth 35) }\end{array}$}} \\
\hline & \multicolumn{2}{|c|}{ Right - tooth center (tooth 45) } & & \\
\hline t-statistics & 3.732 & & 4.486 & \\
\hline$p$ - value & $<0.001$ & & $<0.001$ & \\
\hline
\end{tabular}

TABLE 7. Results of t-test for independent samples for the vestibular thickness on the position 46 and 36 between men and women

\begin{tabular}{|c|c|c|c|c|}
\hline \multirow[t]{2}{*}{ t-test for independent samples } & Vestibular & Thickness & Vestibular & Thickness \\
\hline & \multicolumn{2}{|c|}{ Right - tooth center (tooth 46) } & \multicolumn{2}{|c|}{ Left - tooth center (tooth 36) } \\
\hline t-statistics & 2.411 & & 2.379 & \\
\hline$p$ - value & 0.016 & & 0.018 & \\
\hline
\end{tabular}

TABLE 8. Results of t-test for independent samples for the vestibular thickness on the position 47 and 37 between men and women

\begin{tabular}{|c|c|c|c|c|}
\hline \multirow[t]{2}{*}{ t-test for independent samples } & Vestibular & Thickness & \multirow{2}{*}{\multicolumn{2}{|c|}{$\begin{array}{cc}\text { Vestibular } & \text { Thickness } \\
\text { Left - tooth center (tooth 37) }\end{array}$}} \\
\hline & \multicolumn{2}{|c|}{ Right - tooth center (tooth 47) } & & \\
\hline t-statistics & 0.848 & & 0.328 & \\
\hline$p$ - value & 0.397 & & 0.743 & \\
\hline
\end{tabular}

TABLE 9. Results of t-test for independent samples - comparison of the difference between the right and left mandibular side

\begin{tabular}{lccc}
\hline $\begin{array}{l}\text { t-test for independent } \\
\text { samples }\end{array}$ & $\begin{array}{c}\text { Vestibular thickness - } \\
\text { Tooth center (45-35) }\end{array}$ & $\begin{array}{c}\text { Vestibular thickness - } \\
\text { Tooth center (46-36) }\end{array}$ & $\begin{array}{c}\text { Vestibular - Thickness } \\
\text { tooth center (47-37) }\end{array}$ \\
\hline t-statistics & -0.667 & 0.087 & 0.622 \\
$p$ - value & 0.505 & 0.931 & 0.534 \\
\hline
\end{tabular}

either side in the case of vestibular bone thickness of the center of the second molar (Table 8).

Based on test results in Table 9, the conclusion is that there does not exist a statistically significant difference in the comparison of vestibular bone thickness measured on centers of teeth between the left and right side of examinees divided according to gender.

Table 10 demonstrates statistically significant differences between the second premolar and first molar and also between the second premolar and second molar with men on both sides of mandible. Furthermore, the same statistically significant differences exist with women. Based on the mean values shown in Tables 3-5 and based on the results of post host tests, a statistically significant difference exists between different groups of teeth.

One-way ANOVA test demonstrated no statistically significant difference in the vestibular bone thickness measured on the center of the second premolar, first molar, and second molar between different age groups (Table 11).

\section{DISCUSSION}

Out of 700 examined patients in research, 322 met inclusion criteria for the analysis, and this number of patients
TABLE 10. Result of post hoc test for men and women and for the right and left side between different groups of teeth

\begin{tabular}{cc}
\hline Gender & $p$-value \\
\hline Men & \\
Right side & \\
$45-46$ & $<0.0001$ \\
$45-47$ & $<0.0001$ \\
Left side & \\
$35-36$ & $<0.0001$ \\
$35-37$ & $<0.0001$ \\
Women & \\
Right side & \\
$45-46$ & $<0.0001$ \\
$45-47$ & $<0.0001$ \\
Left side & \\
$35-36$ & $<0.0001$ \\
$35-37$ & $<0.0001$ \\
\hline
\end{tabular}

was subjected to statistical analysis following the conducted measurements on CBCT images. The ratio of men and women was approximately equal and it totaled 159:163.

After the measurement of average values of vestibular bone 75 thickness of the mandible in relation to the mandibular 
TABLE 11. Results of one-way ANOVA test - comparison of agerelated differences in vestibular bone thickness

\begin{tabular}{lcccccc}
\hline \multicolumn{7}{c}{ One-way ANOVA } \\
\hline Vestibular & Tooth & Tooth & Tooth & Tooth & Tooth & Tooth \\
bone & center & center & center & center & center & center \\
thickness & 45 & 35 & 46 & 36 & 47 & 37 \\
F statistics & 2.154 & 1.041 & 2.056 & 1.364 & 2.233 & 1.298 \\
p-value & 0.118 & 0.354 & 0.130 & 0.257 & 0.109 & 0.275 \\
\hline
\end{tabular}

canal measured at the position of the center of teeth with all patients on the right side of the second premolar, of the first and second molar, it is detected that the largest value is in the area of the second molar and that the lowest one is at the second premolar. The same results were obtained in the research by Safaee, who was also measuring the distance of the mandibular canal from the outer cortex of lingual and vestibular side of the mandible and indicated to the fact that the canal was approaching the lingual side by going posteriorly and that the largest thickness of vestibular side of the mandible in relation to the mandibular canal was in the position of the second molar (18). Balaji et al. in their research also concluded that the largest vestibular thickness of the mandible was in the position of the second molar (19). Koivisto et al. found that buccal bone thickness over the mandibular canal was thickest at mesial root of the second molars and thinnest over the second premolar (5.4 vs. $2.6 \mathrm{~mm}$ ) (20). The study conducted in Switzerland, which was measuring the distance of mandibular canal from the outer cortex of the mandible, by starting to measure this distance at $2 \mathrm{~mm}$ posteriorly from the mental opening indicates that the mandibular canal is more and more distancing itself from the vestibular outer cortex in the first $30 \mathrm{~mm}$ of the measurement and after that it again starts approaching the vestibular cortex of the mandible (21).

$\mathrm{Al}$-Siweedi in his research, just like Valdec, measures the distance of the mandibular canal from the buccal cortex of the mandible and obtains the values of $3.90 \pm 1.01 \mathrm{~mm}$, $5.59 \pm 1.20 \mathrm{~mm}, 6.71 \pm 1.34 \mathrm{~mm}, 5.69 \pm 1.63 \mathrm{~mm}$, and $4.25 \pm 1.60 \mathrm{~mm}$, on positions from $10 \mathrm{~mm}, 20 \mathrm{~mm}$, $30 \mathrm{~mm}, 40 \mathrm{~mm}$, and $50 \mathrm{~mm}$ distally from mental foramen and it is seen that the mandibular canal is distancing itself more and more from the buccal cortex by going from mental foramen, and then probably on the position of the first or second molar (as it is the case of this study) it reaches maximum values of distance from the buccal mandibular cortex and then it approaches to the buccal cortex in lateral segments (22).

Al-Siweedi et al. state that the largest distance of the mandibular canal from the outer buccal cortex was on the position of the second molar with average value of $6.79 \mathrm{~mm}$ (21). Those results agree with research results of Nagadia et al. and Shokri et al. $(23,24)$. In this study, the average vestibular thickness on the position of the second molar was $6.067 \mathrm{~mm}$ on the right side and $6.03 \mathrm{~mm}$ on the left side for men. The mean value of vestibular thickness was $5.935 \mathrm{~mm}$ on the right side and $5.981 \mathrm{~mm}$ on the left side for women.

Many authors claim that from the second premolar distally, the mandibular canal approaches the lingual side (19,22-27). Al-Siweedi et al. also find that it is larger the distance of the mandibular canal from buccal side in relation to lingual side and that is also claimed by Tsuji et al. (28).

In our research, the results demonstrate a smaller distance from the buccal side in the position of the second premolar and as the mandibular canal goes posteriorly, the distance becomes larger, regardless of gender and the side of the mandible, which is in agreement with the research conducted by Shokri et al. and Nair et al. (24,26). With the study of Hsu et al., the average value on the first molar was $4.72 \pm$ $1.72 \mathrm{~mm}$ and it was larger in relation to the second premolar with values of $4.08 \pm 0.98 \mathrm{~mm}$, thus distally buccal thickness increases which are in agreement with the results of our research (29). However, the values obtained in this study are higher than in the study of Hsu et al. The average vestibular thickness on the position of the first molar was $5.97 \pm 1.33$ on the right side and $5.98 \pm 1.27 \mathrm{~mm}$ on the left side for men. In women, the average value was $5.63 \pm$ 1.14 on the right side and $5.65 \pm 1.17 \mathrm{~mm}$ on the left side. By analysis of results of all patients, results have shown that there exist statistically significant differences between men and women on the position of the second premolar and first molar (Tables 6 and 7). Men had on average larger values of vestibular bone thickness compared to women. Valdec et al. found a significant difference for bone thickness between men and women, particularly in the first $30 \mathrm{~mm}$ posterior to the mental foramen. They found that mandible is wider in the area of the mental foramen in men (21).

Similar to the above-mentioned study, we established that statistically significant differences existed with both genders between various measuring points on both sides of mandible. There are statistically significant differences between the second premolar and first molar and also between the second premolar and second molar on both sides on both genders. Thus, it can be concluded that regardless of whether this concerned the first or the second molar for any surgical operation in that area, it is a smaller probability of injuring the first or second molar than the second premolar of any side of the mandible.

The results of researches results differ regarding the issue, whether there exist differences in bone thickness of the mandible in relation to the mandibular canal between men and women. Some research reached the results that differences do exist (19,22,30,31). However, research conducted by some authors has not found statistically significant differences in the position of the mandibular canal and/or in vestibular bone thickness between the genders (15,32-34).

In the present study, there were no significant age-related differences in bone thickness. In their study, Valdec et al. found that bone thickness did not differ between the age groups among men. On the contrary, there were significant age-related differences in women. Their age groups were different than ours (group $1=0-20$ years, group $2=21-$ 40 years, group $3=41-60$ years, and group $4=61$ years and older) and also they included younger patients (21).

\section{CONCLUSION}

1. Mandibular canal in the area of the second premolar is located closest to the outer vestibular cortex with all patients of both genders and on both sides and as the mandibular canal goes posteriorly, the distance 
becomes larger. On the position of the second molar, the mandibular canal is furthest from external vestibular cortex in both genders and on both sides of the mandible. The probability of nerve injury during surgery is higher on the position of the second premolar in relation to both molars on both sides of mandible and on both genders

2. Values of vestibular thickness of the mandible are larger with men than with women in all measuring points; however, statistically significant differences between genders have been detected in the second premolar and center of the first molar on both side of mandible so that men have a lower risk of nerve injury on these positions of the mandible

3. Age does not affect the change in the dimensions of vestibular bone at any measuring point.

\section{DECLARATION OF INTEREST}

No conflicts of interest.

\section{REFERENCES}

1. Worthington P. Injury to the inferior alveolar nerve during implant placement: A formula for protection of the patient and clinician. Int J Oral Maxillofac Implants 2004;19(5):731-4

2. Angelopoulos C, Thomas SL, Hechler S, Parissis N, Hlavacek M. Comparison between digital panoramic radiography and conebeam computed tomography for the identification of the mandibular canal as part of presurgical dental implant assessment. J Oral Maxillofac Surg 2008;66(10):2130-5. https://doi.org/10.1016/j.joms.2008.06.021.

3. Pyun JH, Lim YJ, Kim MJ, Ahn SJ, Kim J. Position of the mental foramen on panoramic radiographs and its relation to the horizontal course of the mandibular canal: A computed tomographic analysis. Clin Oral Implants Res 2013;24(8):890-5. https://doi.org/10.1111/j.1600-0501.2011.02400.x.

4. Levine MH, Goddard AL, Dodson TB. Inferior alveolar nerve canal position: A clinical and radiographic study. J Oral Maxillofac Surg 2007;65(3):470-4 https://doi.org/10.1016/j.joms.2006.05.056.

5. Aloy-Prósper $A$, Peñarrocha-Oltra D, Peñarrocha-Diago AM, Peñarrocha-Diago M The outcome of intraoral onlay block bone grafts on alveolar ridge augmentations: A systematic review. Med Oral Patol Oral Cir Bucal 2015;20(2):e251-8. https://doi.org/10.4317/medoral.20194.

6. Idrontino G, Valente NA. Intraoral and extraoral autologous bone block graft techniques: A review of the recent literature. Int J Contemp Dent Med Rev 2016;2016:030316.

7. Karl E. Mish: Cotemporary Implant Dentistry. $3^{\text {rd }}$ ed. Missouri: Mosby Elsevier; 2008.

8. Misch CM. Comparison of intraoral donor sites for onlay grafting prior to implant placement. Int J Oral Maxillofac Implants 1997;12(6):767-76.

9. Mittal $Y$, Jindal G, Garg S. Bone manipulation procedures in dental implants. Indian J Dent 2016;7(2):86-94. https://doi.org/10.4103/0975-962x.184650.

10. Sittitavornwong $S$, Gutta R. Bone graft harvesting from regional sites. Oral Maxillofac Surg Clin North Am 2010;22(3):317-330. https://doi.org/10.1016/j.coms.2010.04.006.

11. Khoury F. Bone Augmentation in Oral Implantology. London: Quintessence; 2007.

12. Kim YK, Hwang JW, Lee HJ, Yun PY. Use of the coronoid process as a donor site for sinus augmentation: A case report. Int J Oral Maxillofac Implants 2009;24(6):1149-52.

13. Kim IS, Kim SG, Kim YK, Kim JD. Position of the mental foramen in a Korean population: A clinical and radiographic study. Implant Dent 2006;15(4):404-11. https://doi.org/10.1097/01.id.0000243319.66845.15.

14. Rueda S, Gil JA, Pichery R, Alcañiz M. Automatic segmentation of jaw tissues in CT using active appearance models and semi-automatic landmarking. Med Image Comput Comput Assist Interv. 2006;9(Pt 1):167-74.

https://doi.org/10.1007/11866565_21.

15. de Oliveira Júnior MR, Saud AL, Fonseca DR, De-Ary-Pires B, Pires-Neto MA, de AryPires R. Morphometrical analysis of the human mandibular canal: a CT investigation. Surg Radiol Anat 2011;33(4):345-52

https://doi.org/10.1007/s00276-010-0708-3
16. Katakami K, Mishima A, Shiozaki K, Shimoda S, Hamada Y, Kobayashi K. Characteristics of accessory mental foramina observed on limited conebeam computed tomography images. J Endod 2008;34(12):1441-5.

https://doi.org/10.1016/j.joen.2008.08.033.

17. Dean Molen A. Considerations in the use of cone-beam computed tomography for buccal bone measurements. Am J Orthod Dentofacial Orthop 2010;137(Suppl 4):S130-5. https://doi.org/10.1016/j.ajodo.2010.01.015.

18. Safaee A, Mirbeigi S, Ezoddini F, Khojastepour L, Navab-Azam A. Buccolingual course of the inferior alveolar canal in different mental foramen locations: A conebeam computed tomography study of an Iranian population. Int J Appl Basic Med Res 2016;6(4):262-6.

https://doi.org/10.4103/2229-516x.192589.

19. Balaji SM, Krishnaswamy NR, Kumar SM, Rooban T. Inferior alveolar nerve canal position among South Indians: A cone beam computed tomographic pilot study. Ann Maxillofac Surg 2012;2(1):515

https://doi.org/10.4103/2231-0746.95319.

20. Koivisto T, Chiona D, Milroy LL, McClanahan SB, Ahmad M, Bowles WR, et al. Mandibular canal location: Cone-beam computed tomography examination. J Endod 2016;42(7):1018-21. https://doi.org/10.1016/j.joen.2016.03.004.

21. Valdec S, Borm MJ, Casparis S, Damerau G, Locher M, Stadlinger B. Vestibular bone thickness of the mandible in relation to the mandibular canal a retrospective CBCTbased study. Int J Implant Dent 2019;5:37.

https://doi.org/10.1186/s40729-019-0189-z.

22. AlSiweedi SY, Nambiar P, Shanmuhasuntharam P, Ngeow WC. Gaining surgical access for repositioning the inferior alveolar neurovascular bundle. ScientificWorldJournal 2014;2014:719243.

https://doi.org/10.1155/2014/719243

23. Nagadia R, Tay AB, Chan LL, Chan ES. The spatial location of the mandibular canal in Chinese: A CT study. Int J Oral Maxillofac Surg 2011;40(12):14015

https://doi.org/10.1016/j.ijom.2011.07.904.

24. Shokri A, Shakibaei Z, Langaroodi AJ, Safaei M. Evaluation of the mandibular canal visibility on conebeam computed tomography images of the mandible. J Craniofac Surg 2014;25(3):e2737.

https://doi.org/10.1097/scs.0000000000000654.

25. Greenstein G, Tarnow D. The mental foramen and nerve: Clinical and anatomical factors related to dental implant placement: A literature review. J Periodontol 2006;77(12):1933-43. https://doi.org/10.1902/jop.2006.060197

26. Nair UP, Yazdi MH, Nayar GM, Parry H, Katkar RA, Nair MK. Configuration of the inferior alveolar canal as detected by cone beam computed tomography. J Conserv Dent 2013;16:51821. https://doi.org/10.4103/0972-0707.120964.

27. Massey ND, Galil KA, Wilson TD. Determining position of the inferior alveolar nerve via anatomical dissection and microcomputed tomography in preparation for dental implants. J Can Dent Assoc 2013;79:d39.

28. Tsuji Y, Muto T, Kawakami J, Takeda S. Computed tomographic analysis of the position and course of the mandibular canal: Relevance to the sagittal split ramus osteotomy. Int J Oral Maxillofac Surg 2005;34(3):243-6. https://doi.org/10.1016/j.jom.2004.06.001.

29. Hsu JT, Huang HL, Fun LJ, Li RW, Wu J, Tsai MT, et al. Location of the mandibular canal and thickness of the occlusal cortical bone at dental implant sites in the lower second premolar and first molar. Comput Math Methods Med 2013;2013:608570. https://doi.org/10.1155/2013/608570.

30. Fayeda MM, Pazerab P, Katsarosc C. Optimal sites for orthodontic mini-implant placement assessed by cone beam computed tomography. Angle Orthod 2010;80(5):939-51. https://doi.org/10.2319/121009-709.1.

31. Rosa RR, Ribeiro CV, Matai CV, Gomes MB, Guimarães SM, Henriques JC, et al. Quantitative evaluation of posterior mandibular region by cone beam computerized tomography as a donor site for autogenous bone grafts. Rev Odontol Bras Central 2018;27(80):1-5.

32. Kilic C, Kamburoglu K, Ozen T, Balcioglu HA, Kurt B, Kutoglu T, et al. The position of the mandibular canal and histologic feature of the inferior alveolar nerve. Clin Anat 2010;23(1):34-42 https://doi.org/10.1002/ca.20889.

33. Kalabalik F, Aytuğar E. Localization of the mandibular canal in a Turkish population: A Retrospective cone-beam computed tomography study. J Oral Maxillofac Res 2019;10(2):e2. https://doi.org/10.5037/jomr.2019.10202.

34. Ulm CW, Solar P, Blahout R, Matejka M, Watzek G, Grubcr H. Location of the mandibular canal within the atrophic mandible. Br J Oral Maxillofac Surg 1993;31(6):370-5. https://doi.org/10.1016/0266-4356(93)90193-z. 